(4) The needle is released at once by relaxing the /screwed firmly. When it is necessary to refill this grasp and allowing the jaws to open.

The instrument is made by Codman \& Shurtleff, of this city, and the Kriy-Scheerer Company, of New York. $\Lambda$ reference to the cuts, especially to Fig. 2, will make clear, I think, its construction and action. bottle, the upper part of the attachment only is unscrewed, and, after the bottle is filled, this is screwed on again.

To administer ether one has only to tip up the bottle and press the valve hamdle, thus opening the valve,

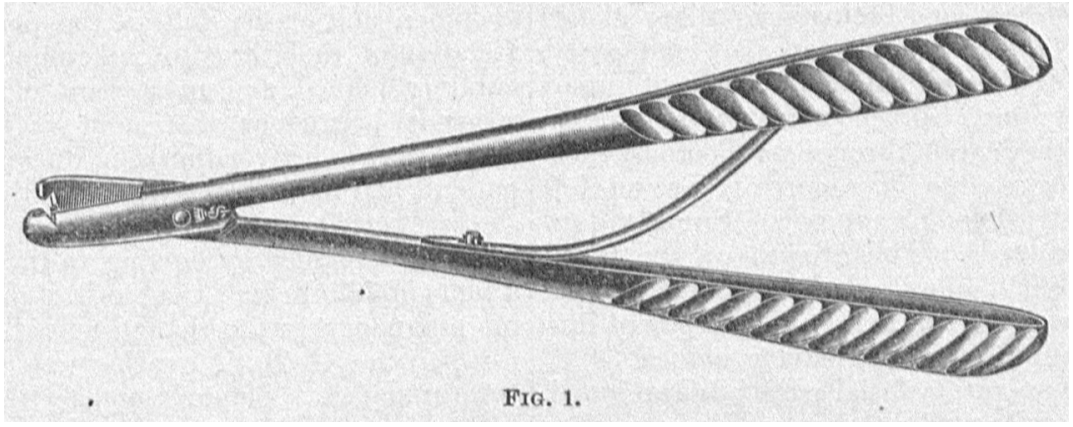

Fig. 1 shows the instrument just as it lies, with open jaws on the instrument table; and Fig. 2 presents these jaws on a larger scale.

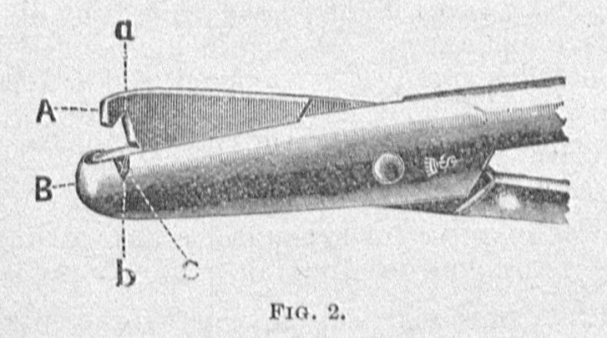

The lower jaw (see Fig. 2, B) consists of two pieces with an interval between, in which interval the upper jaw (A) plays, as the instrument is closed and opened. There is aV-shaped depression (a) in the upper jaw, and corresponding depressions (b) in the lower one. When the jaws close upon a needle, the V's of the lower jaw approach the $\mathrm{V}$ in the upper jaw until the needle is grasped between them. If Fig. 2 be examined closely it will be seen that the V's in the lower jaw seem to be filled up, as it were, by a tongue of metal (c) projecting from a part of the upper jaw. This projecting portion acts as an ejector, throwing the needle out of the V's of the lower jaw whenever the instrument is allowed to open. 'Thuugh different kinds of handles have been used on the nectle-holder, I think that shown in Fig. 1 is the best.

\section{A SELF-CLOSING STOPPER FOR AN ETHER BO'TTLE.1}

HY L. R. G. CRANDON, M.D., HOs'ron, Senior Surgical Interne, Boston City Hospltal.

For the purpose of saving ether and facilitating the work of the etherizer, I recently devised a selfclosing stopper, which has been in practical use for the past six months on the surgical side of the hospital, and seems to have answered the above requirements. The stopper which is shown in the accompanying figure will exactly fit the common flattopped sixteen-ounce bottle, to which it is to be

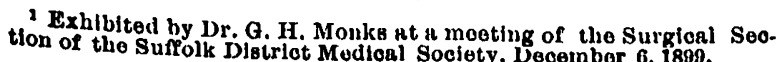

and a continuous stream of ether is directed into the cone. When the pressure is relaxed, the valve closes automatically, and remains closed. The stopper is

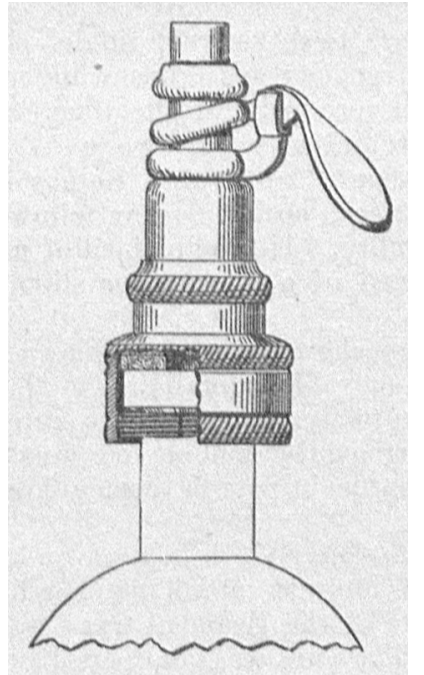

manufactured for the hospital at the Grundy Brass Works, 50 Sudbury St., Boston.

\section{Elinical gDepartment.}

MASSACHUSETTS GENERAI, ITOSPITAI. CLINICAL, MEETING OF 'THE MEDICAL BOARD.

(Concluded from No. 11, p. 276.)

Regular meeting, December 15, 1899, Dr. C. 3 . Porter in the chair.

Dr. C. B. Porter showed the following cases:

I. SARCOMA OF TONSIL.

V. A., age forty-nine. Iron foundry laborer. Four months before entrance noticed a tight foeling at base of tongue. The left tonsil had been enlarging since that time. Has some pain on articulation, which has become more and more indistinct. Mastication is difficult and there is considerable dysphagia, the food seeming to catch behind the growth to drop later and cause choking. He has lost six pounds in two months. 